\title{
COVID-19: Mandatory institutional isolation v. voluntary home self-isolation
}

\author{
J A Singh, BA, LLB, LLM, MHSc, PhD \\ Centre for the AIDS Programme of Research in South Africa (CAPRISA), University of KwaZulu-Natal, Durban, South Africa
}

Corresponding author: J A Singh (singhj9@ukzn.ac.za)

\begin{abstract}
Since community transmission of COVID-19 became established in South Africa, individuals who test positive for COVID-19 and who do not require hospitalisation have been permitted to self-isolate in their homes to reduce the burden on the health system. The Premier of KwaZulu-Natal Province has since announced that self-isolation will no longer be permitted in the province. Instead, mandatory isolation in state-designated isolation sites would apply. This policy change marks a dangerous departure from the country's prevailing position on home-based self-isolation and should not be replicated elsewhere.
\end{abstract}

S Afr Med J 2020;110(6):453-455. https://doi.org/10.7196/SAMJ.2020.v110i6.14840

Despite the South African (SA) government declaring a State of Disaster and subsequently announcing an unprecedented national lockdown to mitigate the spread of COVID-19 in the country, COVID-19 infections in the country have continued to rise. Gauteng, Western Cape and KwaZulu-Natal (KZN) provinces shoulder the highest burdens of COVID-19 cases in the country, with several COVID-19 'hotspots' in these provinces now emerging. Since community transmission of COVID-19 became established in SA, individuals who test positive for COVID-19 and who do not require hospitalisation have been permitted to self-isolate in their homes to reduce the burden on the health system. On 20 April 2020, the KZN Premier announced that self-isolation was no longer permitted in the province. ${ }^{[1]}$ Instead, mandatory isolation in state-designated isolation sites would be enforced. This policy change marks a dangerous departure from the country's prevailing position on home-based self-isolation and should not be replicated elsewhere.

\section{The status of COVID-19 in KZN}

As of 19 April 2020, KZN had 587 COVID-19 infections (18\% of the country's total), with eThekwini District (Durban Metro) constituting $65 \%$ (283) of provincial cases and $77 \%$ of new provincial cases. Of this total, 61 were being treated in private facilities and 22 in public facilities. According to the KZN Premier, 54\% of COVID19 patients in the province were self-isolating at that point. ${ }^{[1,2]}$ As per the Premier's announcement, commencing 20 April 2020, newly diagnosed COVID-19 patients in the province are to be taken to government-approved isolation sites for treatment. To justify the province's change in policy, the Premier stated: 'There's a leakage in the system in so far as self-isolation is concerned, in that those who are self-isolating, far from strict supervision, may interact with others and infect them. ${ }^{[2]}$ The KZN Member of the Provincial Executive Council (MEC) for Health echoed this sentiment, attributing the rise in cases to 'those self-isolating, claiming to be self-isolating, roaming around interacting with families. ${ }^{[2]}$ What, then, is the stance of COVID-19 governance frameworks on selfisolation?

\section{World Health Organization governance on home-based self- isolation}

With regard to COVID-19, in situations where isolation of all cases in a healthcare facility is not possible, the World Health Organization (WHO) emphasises prioritisation of those with the highest probability of poor outcomes ${ }^{[3]}$ If all mild COVID-19 cases cannot be isolated in health facilities, the WHO recommends that those with mild illness and no risk factors be isolated in non-traditional facilities, such as repurposed hotels, stadiums or gymnasiums, where they can remain until their symptoms resolve and laboratory tests for COVID-19 virus are negative. Alternatively, the $\mathrm{WHO}$ recommends that patients with mild disease and no risk factors can be managed at home. To that end, the WHO recommends that if there are patients with only mild illness, providing care at home may be considered, as long as they can be followed up and cared for by family members. The WHO advises that home care may also be considered when inpatient care is unavailable or unsafe (e.g. capacity is limited, and resources are unable to meet the demand for healthcare services). ${ }^{[3]}$

\section{SA governance on COVID-19 isolation}

SA's guideline on preparedness, detection and response to COVID-19, published in January 2020, is silent on self-isolation. ${ }^{[4]}$ Regulations on COVID-19 published in the aftermath of the government's State of Disaster declaration ${ }^{[5]}$ define 'isolation' as meaning 'separating a sick individual with a contagious disease from healthy individuals without that contagious disease in such a manner as to prevent the spread of infection or contamination'. In terms of the regulations, no person who has been confirmed as having COVID-19, or who is suspected of having contracted COVID-19, or who has been in contact with a person who is a carrier of COVID-19, may refuse consent for admission to a health establishment or isolation site. Nor may a person refuse consent for submission to mandatory isolation in order to prevent transmission. The regulations do not define what constitutes an 'isolation site', leaving open the possibility that this could include an appropriate home setting. Notwithstanding the provisions of the 
regulations, the KZN government has noted that its response to COVID-19 is at 'all times ... in line with WHO guidelines which include ... the promotion of self-initiated isolation of people with mild respiratory symptoms to reduce the burden on [the] health system. ${ }^{\text {[6] }}$

\section{Why the new KZN policy on mandatory institutional isolation is flawed}

Coercive power over individuals should be premised on the principles of (i) transparency, (ii) public health necessity, (iii) reasonable and effective means, (iv) distributive justice, $(v)$ proportionality, and (vi) reciprocity. As the Premier's stance is premised on suspicions about current self-isolating defaulters, it is unclear whether KZN's new policy applies to only newly diagnosed cases from 20 April 2020 onwards, and/or also to current self-isolators, who may be defaulting. Given this uncertainty, it is debatable whether KZN's policy satisfies the principle of transparency. To satisfy the principle of necessity, mandatory isolation should be based on a demonstrable threat to public health. In this regard, the KZN government has provided no corroborating evidence to demonstrate that the spread of COVID-19 in the province is attributable to defaulting self-isolators. While this suspicion may be valid in some instances, it is not necessarily universally true. In relevant circumstances, it is undeniably necessary and in the interests of public health to remove an infected individual from their dwelling to safeguard the health of others residing there - say, for example, where all members of the household live in a single-room informal dwelling. However, where an individual is able to self-isolate and does so responsibly, they pose little or no infection risk to others. In such instances, mandatory institutional isolation would be unreasonable and ineffective in containing the spread of COVID-19. Emerging evidence indicates that asymptomatic people who have contracted COVID-19 can be a significant source of infection to others. One study showed that up to $86 \%$ of all infections could be undocumented and such infections could be the infection source for $79 \%$ of documented cases. ${ }^{[7]}$ These undetected cases were responsible for the majority of the disease spread prior to the affected region's lockdown. ${ }^{[7]}$ It is possible that the same factor may be silently driving infections in KZN and elsewhere in SA, rather than defaulting self-isolators. Distributive justice dictates that the risks, benefits and burdens of public health interventions should be shared fairly. By 19 April 2020, KZN had 587 active cases of COVID-19, of whom $54 \%$ were in self-isolation. ${ }^{[1,2]}$ If KZN's new policy applies retrospectively, 317 people who are currently in self-isolation theoretically face mandatory isolation in state facilities. If COVID-19 cases in KZN continue to rise, the province's health system will be overwhelmed, as has been the experience in other settings that have experienced 'surge' scenarios. In preparation for such a context, our goal should be to reserve every available hospital bed dedicated to COVID-19, for COVID-19 patients with the highest probability of poor outcomes. Allocating precious beds to patients who have mild COVID-19 symptoms, especially in a rapidly evolving pandemic context, constitutes an inefficient use of scarce resources and is unsustainable in the medium to long term. Resource scarcity will amplify as the pandemic entrenches itself across the country. Even if infected persons are not isolated in hospital facilities but in other designated isolation facilities, increased surveillance could yield many more COVID-19 cases. If this were to occur, available beds in all isolation facilities will quickly reach their limit. The allocation of beds to individuals with mild symptoms who could self-isolate risks depriving needier infected patients of beds. Further, mandatory isolation based on the damaging generalisation that self-isolators are spreading COVID-19 risks stigmatising those who have the disease, and could discourage active COVID-19 testing and drive the disease 'underground'. Such an outcome will have devastating consequences for KZN and the rest of the country. Given such factors, the KZN government's strategy unduly burdens those able to responsibly selfisolate and could potentially deprive more needy patients of beds, and thus fails the test of distributive justice. If our public health goals are (i) to prevent the spread of COVID-19 by those who are self-isolating, and (ii) to preserve beds for only those patients who truly need them, officials should pursue the least restrictive means to achieve these ends. Doing so satisfies the principle of proportionality. Less restrictive alternative means could include the provision of intensified counselling to encourage self-isolation compliance, random checks on the self-isolating individual by health officials, enforcement officers or community workers, and the levying of penalties for non-compliance, to discourage defaulting. In some settings, including SA, cellphone geospatial data are being used to track the location of infected people. ${ }^{[8]}$ While this use raises privacy issues, in a pandemic context such measures may need to be countenanced if doing so is reasonable and justifiable, and relevant mitigation measures are put in place to mitigate privacy-related risks. ${ }^{[8]}$ As KZN's new policy takes a heavyhanded approach in deference over less restrictive means it fails the test of proportionality. Lastly, the KZN government has not clarified how it plans to manage the social implications of mandatory isolation. If people are being asked to make sacrifices in the interests of the greater good, we should be asking how we can ameliorate their plight and ensure the welfare of their dependants they will be leaving behind. For example, if a household caregiver is infected with COVID-19 and displaying mild symptoms, they face mandatory isolation in terms of KZN's new policy. But who will assume the caregiver's duties (for example, caring for minor children or elderly parents) in their absence when they are isolated away from home? Further, poor conditions at isolation (and quarantine) facilities could see people abscond, which will threaten public health. A failure to prospectively ensure the welfare of individuals at such facilities and their dependants at home fails the principle of reciprocity.

\section{Conclusions}

Mandatory hospital isolation should be decided on a case-by-case basis, be evidence-based, and be reserved for those with the highest probability of poor outcomes. In a pandemic scenario, self-initiated isolation of people with mild respiratory symptoms could help reduce the burden on the health system. Feasibility is also crucial. The use of isolation facilities for individuals infected with COVID-19 who have mild symptoms and who are able to responsibly self-isolate constitutes an inefficient use of scarce resources and is unsustainable in a rapidly evolving pandemic context. Mandatory isolation also risks stigmatising those infected with COVID-19, and could drive the disease underground. We cannot afford to score own goals at this critical juncture in our response to the COVID-19 pandemic.

\section{Declaration. None.}

\section{Acknowledgements. None.}

Author contributions. Sole author.

Funding. Jerome Amir Singh is supported by the Centre for the AIDS Programme of Research in South Africa (CAPRISA), Durban, South Africa. He is also supported by the HIV Prevention Trial Network and the Bill and Melinda Gates Foundation. No specific funding was received for writing this article. The funders had no role in study design, data collection and analysis, decision to publish, or preparation of the manuscript. The views of the writer do not necessarily reflect the views of his funders or employers.

Conflicts of interest. None. 
1. Zikalala S. Tightening of coronavirus COVID-19 regulations at eThekwini. South African Government, 19 April 2020. https://www.gov.za/speeches/premier-sihle-zikalala-tightening-coronavirus-covid-19regulations-ethekwini-19-apr-2020 (accessed 21 April 2020).

2. Erasmus D. KZN enters its 'concomitant punishment' phase on Monday as lockdown is intensified. Daily Maverick, 20 April 2020. https://www.dailymaverick.co.za/article/2020-04-20-kzn-enters-itconcomitant-punishment-phase-on-monday-as-lockdown-is-intensified/ (accessed 21 April 2020).

3. World Health Organization. Home care for patients with COVID-19 presenting with mild symptoms and management of their contacts: Interim guidance. 17 March 2020. https://www.who.int/publicationsdetail/home-care-for-patients-with-suspected-novel-coronavirus-(ncov)-infection-presenting-withmild-symptoms-and-management-of-contacts (accessed 20 April 2020).

4. Department of Health, South Africa. South Africass standard operating procedures for preparedness, . Department of Health, South Africa. South Africas standard operating procedures for preparedness,
detection and response to a coronavirus (2019-ncov) outbreak in South Africa. 30 January 2020. https:// www.hpcsa.co.za/Uploads/Publications\%202020/Resources/SOP_Coronavirus_29_Jan_2020.pdf (accessed 20 April 2020).
5. Regulation 4(1), Government Notice No. 318 of 18 March 2020, as amended by Government Notice No. R. 398 of 25 March 2020. https://www.gov.za/sites/default/files/gcis_document/202003/regulations. pdf (accessed 19 April 2020).

6. KwaZulu-Natal Government. Novel coronavirus (COVID-19). Talking points. http://www.kznonline gov.za/index.php/component//2/item/1157-novel-coronavirus-covid-19 (accessed 20 April 2020).

7. Li R, Pei S, Chen B, et al. Substantial undocumented infection facilitates the rapid dissemination of novel coronavirus (SARS-CoV2). Science 2020 (epub 16 March 2020). https://doi.org/10.1126/science.abb3221 8. Department of Justice and Constitutional Development, South Africa. Minister Ronald Lamola appoints Justice Kate O'Regan as Coronavirus COVID-19 Designate Judge. 3 April 2020. https://www.gov.za/ Justice Kate O'Regan as Coronavirus COVID-19 Designate Judge. 3 April 2020. https://www.gov.za/
speeches/minister-ronald-lamola-appoints-justice-kate-0\%E2\%80\%99regan-coronavirus-covid-19designate-judge-3 (accessed 20 April 2020).

Accepted 22 April 2020. 